\title{
LESSONS LEARNT FROM THE RECONSTRUCTION OF THE DESTROYED MAUSOLEUMS OF TIMBUKTU, MALI
}

\author{
T. Joffroy ${ }^{1, *}$, B. Essayouti ${ }^{2}$ \\ ${ }^{1}$ CRAterre-ENSAG, AE\&CC, Univ. Grenoble Alpes, Grenoble, France - joffroy.t@ grenoble.archi.fr \\ ${ }^{2}$ Mission culturelle de Tombouctou, Tombouctou, Mali - benessayouti@gmail.com
}

\author{
Commission II - WG II/8
}

KEY WORDS: World heritage, Post conflict, Reconstruction, Resilience, Traditional conservation

\begin{abstract}
:
In 2012, the mausoleums of Timbuktu were destroyed by members of the armed forces occupying the North of Mali. After liberation in January 2013, a joint process was launched by the Ministry of Culture of Mali, UNESCO, and the local stakeholders for the gradual reconstruction of these mausoleums, completed in 2016. This has been a long process for heritage structures which, at first glance, appear rather simple and small. However, based on the observations made during the first evaluation mission undertaken in May 2013, it appeared that this question is quite complex. In fact, most of the mausoleums - some at least five hundred years old had been subjected to numerous changes during their history. This provided a large amount of very interesting new information on the mausoleums, leading to a complete revision of the interpretation of their physical nature and that of their surroundings, as well as of their associated intangible heritage and values. This has also led to numerous questions and discussions concerning the way they should be re-built, including the argument that some of the building techniques had not been used for several decades, and there was a potential need for regular maintenance in the long term. After the description of the process, and discussing the findings and decisions made in the various phases, this paper presents a series of lessons learnt before concluding with some remaining questions.
\end{abstract}

\section{INTRODUCTION}

Following a long period of tension, on January 17, 2012, the Malian army officially entered into conflict with some armed groups in the northern zones of the national territory. This conflict somehow worsened due to the coup d'état of March 21, 2012, as the destabilization of the Malian army facilitated the advance of these armed groups to the south. They successively took the cities of Kidal, Gao and Timbuktu and began to settle and impose their rule in almost all zones of Mali to the north of the Niger River.

In addition to imposing a rigorous interpretation of the Sharia ${ }^{1}$, this occupation took material form in moral and cultural pressures on the local populations, with women forced to wear veils and the imposition of many prohibitions (games, music, sport) ${ }^{2}$. Moreover, they went so far that they purposely destroyed ancient manuscripts and fifteen mausoleums associated with saints located in or near the city of Timbuktu inscribed on the World Heritage List in $1988^{3}$. The destruction of these mausoleums in Timbuktu (Figure 1) was undertaken in several stages by Ansar Eddine and $\mathrm{Al}$ Qaeda in the Islamic Maghreb (AQMI). In addition to the alleged religious reasons ${ }^{4}$, this destruction was designed to provoke the international community. In fact, the most important wave of destruction (Figure 1) took place while the 36th meeting of the World Heritage Committee was being held in St. Petersburg in Russia, from June 24 to July 6, 2012.

Corresponding author

Islamic law

2 Dramatic testimony of this situation was provided to us by the Chef de Mission Culturelle de Kidal when he managed to travel to Bamako in December 2012.

3 The World Heritage Sites in Timbuktu are the three older mosques of the city and sixteen mausoleums, three of which are located in Kabara, a nearby village/port on the north bank of the Niger River.

4 The armed groups saw the presence of mausoleums as a religious practice of inadmissible idolatry.

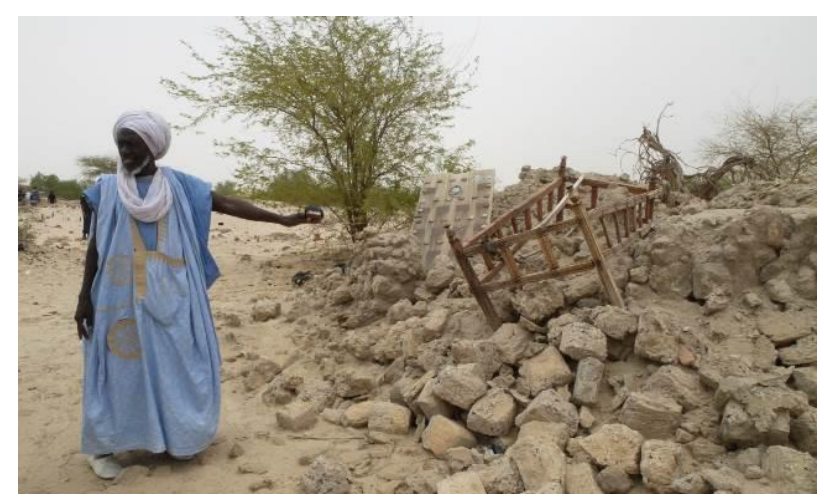

Figure 1. Mausoleum of Cheik Sidi Ben Amar, destroyed on June 30, 2012 @ Joffroy T. CRAterre.

This destruction was revealed by the delegation from Mali which was attending this important annual meeting of the signing parties of the 1972 convention. This led to an impassioned appeal from the Director General of UNESCO, Mrs. Irina Bokova:

Nothing can justify such destruction and I call on all the parties involved in the conflict to put an end to these terrible and irreversible acts, to exercise their responsibilities and to protect this invaluable cultural heritage for future generations

The World Heritage Committee immediately took this appeal into account. Through Decision 36COM 7B.106 Timbuktu serial property and the Tomb of Askia in Gao were registered on the List of World Heritage in Danger. As a logical follow-up to this decision, the World Heritage Center opened a special account in Mali for the safeguarding of its cultural heritage affected by the conflict, with funding allocated from the UNESCO Emergency Fund. 
In the meantime, Mali had joined the 1999 Second Protocol of the Convention for the Protection of Cultural Property in the Event of Armed Conflict (1954 Hague Convention), thus allowing it to benefit from additional attention, in particular from the Blue shield. This resulted in the preparation of a "heritage passport" and maps 5 to be used by the Malian army in the event of a counterattack.

Early in 2013, a counterattack was launched in a common effort by both the Malian and French armies. On January 28, 2013, Timbuktu was liberated and a few days later, French President François Hollande visited the city with the Director General of UNESCO, Mrs. Irina Bokova.

This was followed by the organisation of an international meeting at UNESCO Headquarters in Paris - on February 18, 2013 - which resulted in a common declaration by Mali, France and UNESCO : "Nous reconstruirons les mausolées de Tombouctou". This led to the launch of a joint project which took little over three years to be completed. Three years after its completion, some very interesting lessons can be learnt from both the project and some recent observations made at the mausoleums in relation to the current overall situation in Timbuktu and Mali.

\section{SOURCES OF INFORMATION AND METHODOLOGY}

This paper is based on the documentation existing prior to and produced during the project studied (see selected bibliography). However, in this case both authors have been directly involved in the DNPC 6 - UNESCO programme for the reconstruction of the heritage in the northern zones of Mali from the very beginning.

Thierry Joffroy of CRAterre ${ }^{7}$ had already worked with the Mission culturelle de Tombouctou in 1996 while also being involved in a number of studies undertaken with Ali Ould Sidi ${ }^{8}$, leading to a number of publications on the heritage of Timbuktu, with a specific interest in the traditional conservation practices $^{9}$ of the masons' corporation. His further participation in the study and conservation activities at the World Heritage sites of Gao, Bandiagara and Djenné gave him a leading role in the preparation of the heritage passport and maps produced by UNESCO in 2012.

He was subsequently asked to participate in all the preparatory events and further the elaboration of both the strategic plan and the project document used by UNESCO to raise funds. He also participated actively as advisor throughout the reconstruction process, undertaking evaluation missions on a regular basis (three to four per year).

5 A3 double-sided map and small brochure entitled "Passeport pour le patrimoine du Nord du Mali". https://whc.unesco.org/en/news/981

6 DNPC: Direction Nationale du Patrimoine Culturel, an organisation of the Ministry of culture

CRAterre, international centre for earthen architecture, Thierry Joffroy is also a researcher (HDR) at the school of architecture, AE\&CC research unit, Univ.Grenoble Alpes.

8 Ali Oud Sidi was the first "Chef de la mission culturelle de Tombouctou", an organisation under the DNPC created in 1993 with similar structures also in Djenné and Bandiagara.

9 This first study in Timbuktu has been the starting point of a larger research on the topic which was published by ICCROM entitled: Traditional conservation practices in Africa, ICCROM, 2006. https://www.iccrom.org/publication/traditional-conservationpractices-africa.
Ben Essayouti has been the Chef de la mission culturelle de Tombouctou since 2013 and was actually one of the first representatives of the Malian government to return to Timbuktu following the liberation in 2013. He has played a key role in establishing good links between the Government, international organisations, and the local authorities and people, as well as with the heritage custodians and the masons' corporation. Still in this position, Ben Essayouti is undertaking regular inspection visits to heritage sites in Timbuktu.

At the end of December 2019, he organised a specific inspection tour of all the mausoleums included in the DNPCUNESCO reconstruction programme to obtain first-hand and fresh information for the preparation of this paper. This included interviews with most of the main traditional custodians and stakeholders in order to gain a proper understanding of people's attitude and behaviour in relation to the reconstructed mausoleums.

\section{OBJECTIVES AND DEFINITION OF A STRATEGY FOR THE RECONSTRUCTION}

While some basic aims had already been set at the time of the international experts' meeting organised in Paris on February 18,2013 , reports on the state of conservation of the affected heritage in Timbuktu had remained very general. They only contained partial information on the level of destruction and current condition, and were not very clear on the question of how people's self-confidence in their culture could be affected.

Therefore, UNESCO ${ }^{10}$ decided to organise several missions, first with a group of national experts (architects and heritage specialists) from May 28, and later involving international experts ${ }^{11}$. This first international assessment mission took place on June 6 (Figure 2).

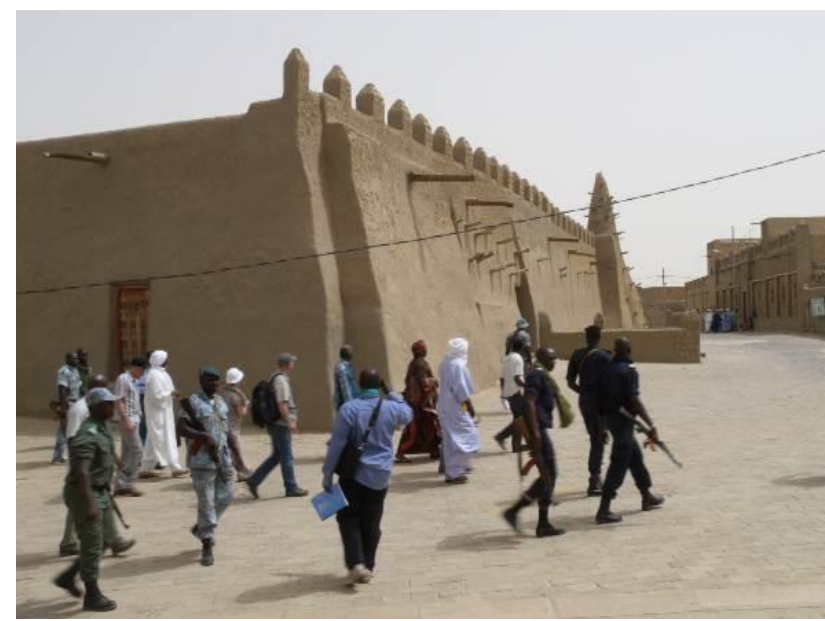

Figure 2. Inspection of Djingarey-ber mosque on June 6, 2013 (C) Joffroy T. CRAterre.

This mission in the field was immediately followed by a national seminar organised on June 8 for all the experts who had been able to visit Timbuktu to share observations, data collected and points of view. It was also aimed at setting priorities, defining a set of guiding principles to be respected when planning and further implementing the reconstruction programme.

\footnotetext{
10 Led by Lazare Eloundou Assomo

11 Including Thierry Joffroy
} 
Therefore, the overall concept arising from this national seminar was to:

\section{Establish an action plan structured into four axes:}

- To study and increase knowledge;

- To restore and rebuild;

- To strengthen institutional and professional capacities;

- To capitalize and disseminate results.

\section{Adopt five main guiding principles:}

- To operate to support Mali in its reconstruction, reconciliation, peacebuilding and social cohesion efforts;

- To focus on the Mausoleums while taking stock of the overall situation in Timbuktu;

- To ensure the strong involvement of traditional managers (owners and corporation of masons) and facilitate the training of young masons;

- To give priority to the use of local building materials while allowing some flexibility when necessary to adapt to contemporary needs and expectations;

- To use this focus on built heritage to consider possible actions for the improvement of housing.

As the first strategic axis clearly indicates, it did appear very clearly to the experts gathered together for this national seminar that additional information should be gathered before the final comprehensive and detailed plan could be defined.

\section{SUPPLEMENTARY INVESTIGATIONS}

Thus, in parallel to the preparation of both the strategic and project documents to be submitted to potential donors, a number of supplementary investigations to be conducted in the field were launched. This also comprised an effort to identify and compile all existing documents and to ensure that some studies would be completed and published (Apollonj Ghetti, 2014; Bertagnin, Ould Sidi, 2014).

The investigations carried out in situ included in-depth architectural and condition surveys, archaeological digs, collection of oral traditions, and a study of the history and significance of the mausoleums. These were undertaken by experts in each of the disciplines concerned. However, a discussion group was set up to make sure that information could be circulated and crosschecked. This proved to be especially interesting when raising questions, while also facilitating interpretation of what was revealed, found or simply observed. Given its success this methodology was adopted during the whole reconstruction process.

The architectural surveys ${ }^{12}$ made it possible to establish a classification framework for the mausoleums, mostly based on their size and building systems: 1) room-like building, 2) 30$50 \%$ scale room-like building, 3) enclosures, and 4) low structures with small pinnacles at the four corners. They revealed that a great variety of building techniques has been used over the last five hundred years: hand shaped mud bricks, raw and dressed limestone (alhore) ${ }^{13}$; mud mortar and plasters; cement mortar for pointing stone masonry (more recent practice); palm tree trunks, branches, plant stems and mats for

12 Conducted by Mamadou Koné, Architect, AUDEX, Bamako

13 The name pierre d'Alhore is used for the limestone locally available which presents a great variety of mechanical resistance as well as a capacity to behave well under damp conditions depending on the layers from which it is extracted. the roofing, etc. It also revealed a wide range of maintenance practices (and their link with intangible practice) as well as repairs, and that some reconstruction works had already taken place in the past. Following these surveys, extensive works were identified - doubling of the original walls with an additional cement-pointed limestone layer - which had been carried out about twenty years ago at some of the mausoleums, though few records are available. This was important information which helped define what the original shape and thickness of the walls would have been.

Several archaeological digs - limited to exploratory pits located beside the gate, as authorized by the custodians - were also undertaken ${ }^{14}$. These showed that some of the mausoleums had a very long history ${ }^{15}$ with both continuity and rupture. The stratification observed inside the excavated mausoleums revealed that these had already been prone to several - if not many - deterioration / repair cycles. Some of the findings at some strata gave clear evidence that the roof had collapsed and had been rebuilt without trying to re-use or remove the collapsed elements ${ }^{16}$. It was also observed that the walls had been raised above the original structures and that this had been done on several occasions. As a result, the buildings that we knew before their destruction by the armed groups in 2012 were in fact located far above the original ones. Explorations only went $3 \mathrm{~m}$ deep as going further would have involved digging larger pits and installing struts, something which the traditional custodians would not have been willing to accept (Figure 3).
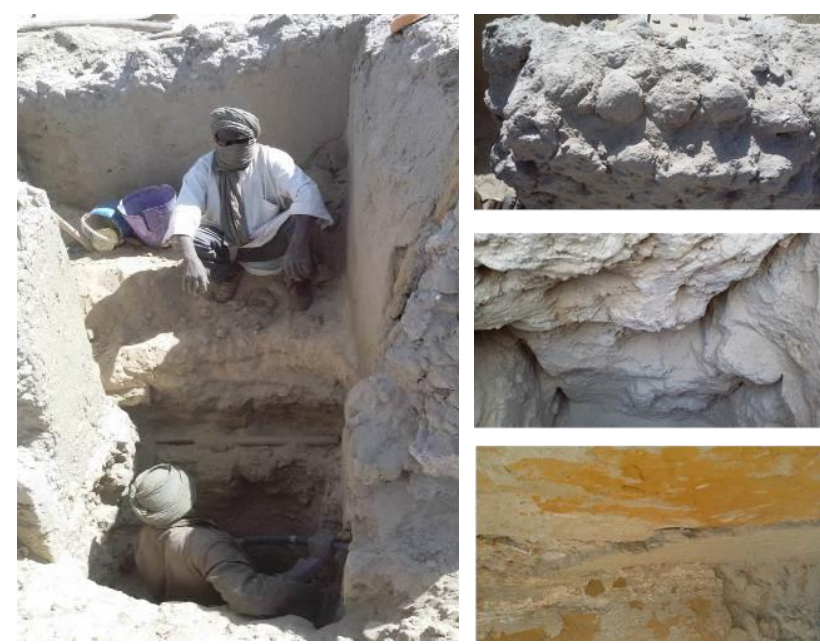

Figure 3. One of the archaeological digs and samples of strata observed (C) Yamoussa F. DNPC.

When connecting this archaeological study to the oral tradition ${ }^{17}$, the known dates of the death of the Saints, and the topography of the cemeteries around the mausoleums ${ }^{18}$, it has been estimated that the original floors of some of the mausoleums (e.g. Alpha Moya) could have been up to $8 \mathrm{~m}$ below the current ones.

14 Conducted by Yamoussa Fané, archaeologist, DNPC Mali.

15 The tradition of building mausoleums in Timbuktu dates back to the 16th century (Cheiks Al Tawaty, Alpha Moya and Ben Omar).

16 This seems to be a normal practice. In the local tradition, it is strictly forbidden to take anything away from a sacred building, even if to external eyes, such a thing could easily be considered waste.

17 Oral tradition recounts that some Saints (Cheiks) were buried in the reception room of their own houses.

18 The prestige of the saints is so high that it is an honor for people to be buried close to them. This gradually elevates the ground level around the mausoleums, and also led to re-elevating the whole structure (walls and roof) at intervals. 
On the intangible aspects, several studies were conducted based on the collection of oral traditions and existing knowledge from traditional historians. This was extremely useful as it provided information never before published on the perception and role ${ }^{19}$ of the saints in Timbuktu. This also covered the rituals and practices linked to them, and what material form these take at the mausoleums when they exist ${ }^{20}$. It also revealed that there were some specific families responsible for looking after these structures and making them accessible. Traditionally, the regular maintenance is the responsibility of a dedicated family of masons. Interestingly, this description allows us to establish some kind of continuity with a very common ancient ritual in Africa - still very much alive - that of linking the re-plastering tradition to that of praying for rain $^{21}$ searching for good agricultural harvests leading to prosperity.

This work has provided the opportunity to acquire sufficient information on the long list of Saints of Timbuktu and even though they do not cover the legendary / magic number of three hundred and thirty three, UNESCO decided to publish this (Ould Elhadj, 2017) as a unique testimony of this intangible heritage, long-known but never previously described.

All this information contributed to the analysis of the experts from the national working group (and their advisors) aiming to finalise the strategic and project documents. But on September 28, 2013, a car-bomb attack was carried out against the army camp ${ }^{22}$ located close to the Djingarey-ber mosque.

This caused a very strong feeling of insecurity, which put a stop to the gathering of information referred to above, resulting in several months of delays for this preparation phase.

Therefore, as the strategic project document was not completed until February 2014 it was possible to organise a national meeting to make the final needed adjustments and validate them. Although security conditions are still equally uncertain, UNESCO has managed to raise sufficient funding for implementation of the planned activities and to secure the collaboration of the MINUSMA ${ }^{23}$ which was to play a paramount role in making the reconstruction project possible.

19 In addition to being seen as protectors of the city, an important role of the Saints is that, as wise people fluent in Arabic, they would be better able to properly transmit people's thoughts, prayers and invocation to God (Allah) than the people themselves. Also being closer to God than the living, they act as translators / message carriers.

20 Some saints, despite their importance did not have mausoleums built to give material form to their memory (as in the case of Ahmed Baba, who gave his name to the major manuscript library and research centre in Timbuktu).

21 The regular maintenance of the mausoleums is to be undertaken every two to three years applying a thick layer of mud plaster, with particular attention to the eastern elevation which is very much exposed to the driving rain. It is not done to try to make the place look beautiful after the rains, but during the month of May, before the rainy season and at a time for praying for rain. This periodic activity is the same for the mosques throughout the region and this ritual is probably very ancient. For example, it is a very lively tradition in the major ancient temples of the Dogon people (Cissé, Joffroy, Guindo, 2010) with the added application of painted decorations as an offering to the "deity of rain".

22 The camp of Cheick Mahamane Tamba Tamba is the location of one of the destroyed mausoleums.

23 MINUSMA is the United Nations Multidimensional Integrated Stabilization Mission in Mali. It was established in 2013 with an extended mandate to facilitate the protection and conservation of World Heritage properties and further tangible and intangible heritage in Mali.

\section{RECONSTRUCTION PROJECT IMPLEMENTATION}

The official launch of the project was organised on March 14, 2014. Apart from the officials present to celebrate the event, on a more religious note, a series of long prayers were organised under the direction of the Imam of Djingarey-ber mosque. Additionally, a sacrificial event was organised by the masons' corporation, in line with the ancient African traditions to be followed when building work is undertaken at a sacred place, whether construction, regular cleaning and maintenance or occasional repairs.

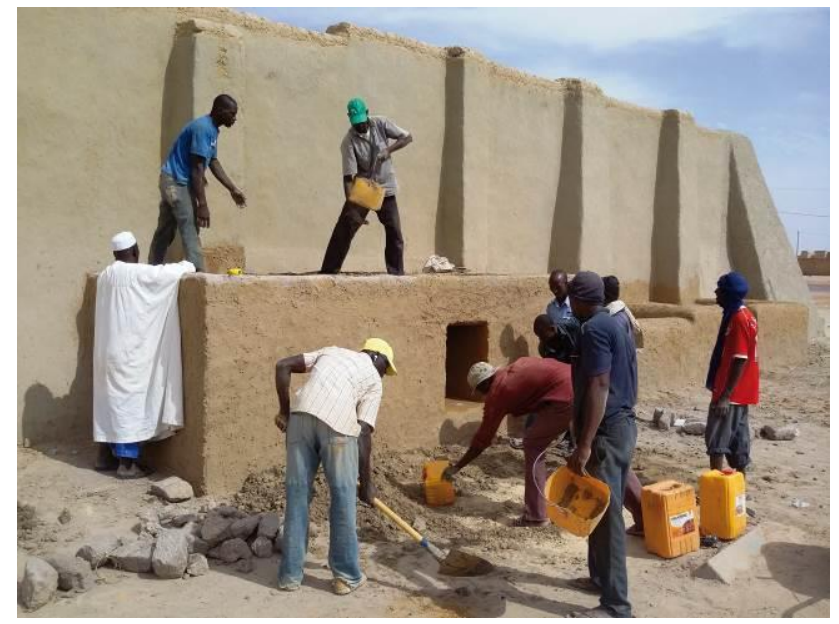

Figure 4. The pilot reconstruction project at the juxtaposed mausoleums of Cheikh Sidi Mahamane al Foulani and Cheikh Sidi Baber Baba Idjé (C) Koné M., Audex.

The reconstruction was planned as an iterative process. The idea thus was to start with one of the smaller mausoleums and possibly in a place which was both safe and easily accessible. Fitting these criteria, the cautious choice for this first activity was that of the two juxtaposed mausoleums of Cheikh Sidi Mahamane al Foulani and Cheikh Sidi Baber Baba Idjé, located against the west wall of the courtyard of the Djingarey-ber mosque, along one of the main streets of the city. This (re)construction site was a chance to organise discussions between conservation experts and traditional masons, using it as a sort of structural model of the larger mausoleum structures (40-50\% scale) to be reconstructed. This allowed them to check different information on the building materials (stones, two kinds of earth, palm trees and branches, etc.), their origin and selection criteria, building techniques, tools and methods on the (re)construction site.

An evaluation of this first sample work was carried out after the 2014 rainy season. This led to some adjustments, which mostly concerned the size and shape of the waterspouts and the composition of the mortar for the plastering.

The waterspouts needed to be much longer and more sloping to project rain water far enough from the wall to avoid drips on the plaster (due to wind) and also to protect the base of the structure from splashing and pools of water that could lead to wall base degradation.

The plastering was only partially satisfactory and the superficial erosion after just a season (though quite a good one) led to reconsidering its composition. The issue had been discussed earlier, some advocating adding more sand to avoid cracks and get a smooth surface, others preferring a high clay content, 
including more straw to provide a thicker layer with a raw finish, locally called sanfa sanfa, with handprints clearly visible on the surface, breaking the speed of the water and thus erosion. Under pressure from those who wanted a very neat, smooth surface for the finish, the sandy solution was selected for the pilot project. However, as foreseen, it did not prove satisfactory. Thus, the later recommendation, sanfa sanfa, was the one finally chosen for the overall project as it offered greater protection to the eastern elevations by adding additional layers (2). This required a search for potential new quarries for the Terre de bas-fond ${ }^{24}$ as those close to Timbuktu appeared to have already been overexploited and so had limited potential for ensuring both quantitative and qualitative requirements for the mausoleums and the other projects planned (maintenance / repair / partial reconstruction).

A better knowledge of the locally available limestone was also acquired, allowing the establishment of rules for selection to adapt to different parts of the buildings and possibly rejecting some lots. This can simply be done with a "hammer test". The sound is more piercing for hard stones to be used in the foundations, while rapid breakage shows poor performance.

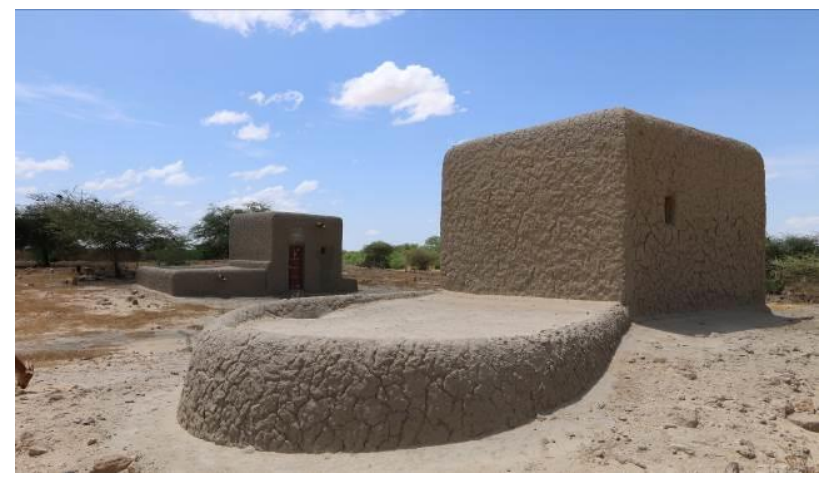

Figure 5. Mausoleums of Cheik al Tawaty (front) and Cheik Sidi Mohammed Mikki (back) after reconstruction, September 2015. (C) Joffroy T. CRAterre.

The second phase (Figure 5) was planned taking into account the results of the pilot reconstruction project beside Djingareyber, both technically and for the estimation of costs needed to ensure the proper involvement of young masons alongside their elders (Figure 6).

Based on the evaluation of the implementation of the second phase some more adjustments were made, mostly concerning the organisation of the site works to become more efficient both in terms of speed and quality of work and to reinforce the dissemination of good practices between the different teams formed and among the younger generations of masons. It was decided to increase the thickness of the plastering layers and to add a third coating on the eastern elevation, more exposed to driving rain. Interior plastering with Terre de Bourem $^{25}$ was also introduced. This third phase was a chance to record all the technical data to produce a mausoleum construction and maintenance guide (Koné, 2015) to be disseminated within the masons' corporation.

24 Terre de bas-fond is composed of an accumulation of fine particles of soil carried by rainwater to characteristically low ground. At some point, these deposits may have been completely excavated by people for their plastering needs, while there is potential for re-generation, although this takes many years over successive rainy seasons.

25 A very special bright yellowish sandy soil, used in the past for highquality interior plastering.

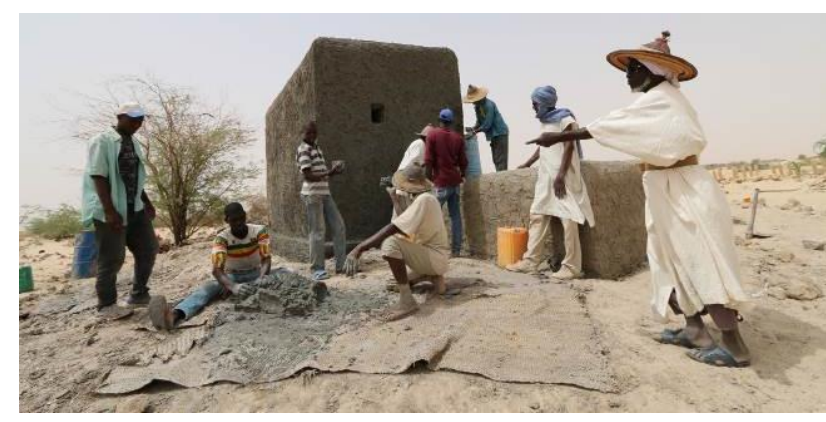

Figure 6. Preparation of mortar for plastering by young masons supervised by the head of the masons' corporation. Mausoleum of Cheik Sidi Ben Amar, April 2015 @ Joffroy T. CRAterre.

Both phases 2 and 3 included larger and smaller mausoleums to be reconstructed. An important criterion for being in the third phase was that of complexity. Thus, the Mausoleum of Alpha Moya (Figure 7) with its very distinctive semi-pyramidal shape and some old broken walls was part of this phase. It also included the three mausoleums located in Kabara, the port city $15 \mathrm{~km}$ from Timbuktu on the north bank of the Niger River where safety conditions were sufficiently ensured to allow the architects and the head of the masons' corporation to supervise on a regular basis.

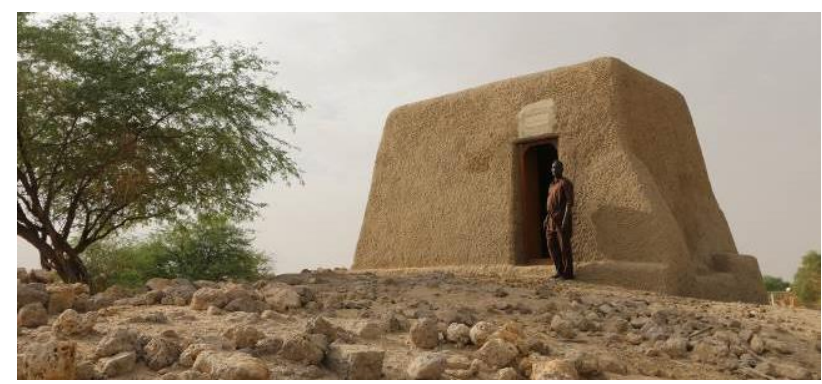

Figure 7. Mausoleum of Cheik Alpha Moya after its reconstruction - September 2015. (C) Joffroy T. CRAterre.

\section{AN INTEGRATED PROJECT}

An important aspect of the project was the drive to include the reconstruction of the mausoleums in an overall strategy aimed at revitalising building traditions and ensuring their continuity. This took material form through on-the-job training activities, while also implementing additional conservation projects. These have involved the three mosques listed as World Heritage Sites, several libraries and two museums.

For the mosques, funding was allocated mostly to facilitate maintenance (Figure 8) and to implement preventative conservation measures. Some more important conservation works were also implemented.

At Djingarey-ber, part of the minaret was dismantled and rebuilt as cracks had appeared following the nearby car bomb in December 2013.

At Sankoré, the overall peripheral superficial drainage was revised and part of the roof renewed.

At Sidi-Yahia, the minaret was consolidated while larger works were to be implemented in the courtyard with problems caused by neighbouring houses which had been abandoned during the occupation. However, the most important achievement at Sidi Yahia has been the restoration and rehanging of the "sacred door" of the adjacent cemetery which had also been destroyed. 
Concerning the manuscript libraries and museums, the opportunity of the DNPC-UNESCO project was an opportunity to undertake more in-depth work with the objective of updating the quality of both storage and valorisation of the collections. All these works have also been an opportunity to favour interaction between old and young masons and to maximize the transfer of knowledge and know-how.

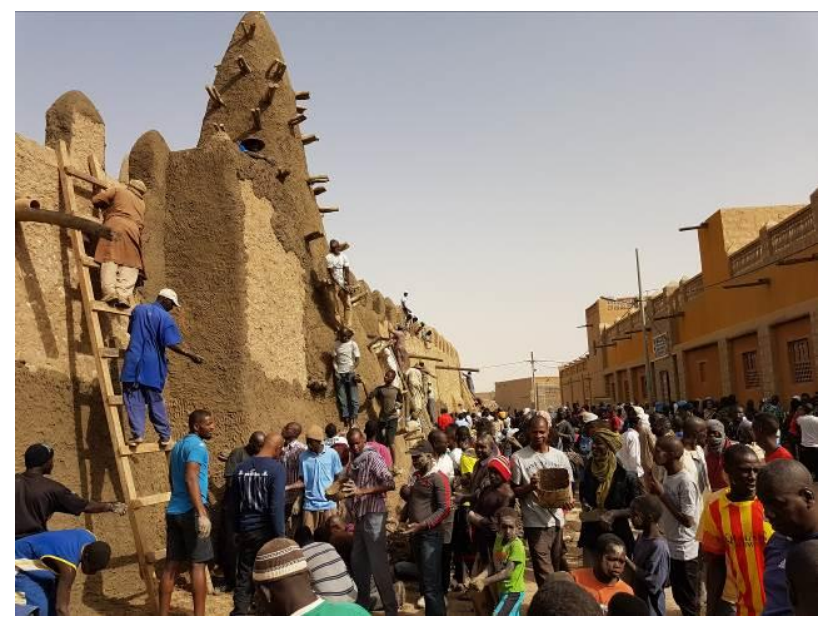

Figure 8. Traditional plastering of Djingarey-ber mosque by the masons and the community of Timbuktu on February 19, 2017. (C) UNESCO - Bagayoko M.

Moreover, the project managed to positively combine heritage conservation with the needs of the affected population for recovery. With the help of $\mathrm{AIMF}^{26}$, a series of interventions were planned within the old town to assist a selection of inhabitants whose family structure had been affected by the occupation (directly or indirectly through family members having migrated to the south, mainly to Bamako). Two series of works were implemented, with a strict selection of the beneficiaries by representatives of the municipality and condition surveys carried out by national architects, taking into account guidance provided by the project for the purpose. This project lasted three years and made it possible to undertake preventive measures and urgent repairs at twenty-five private properties in the old city centre, contributing to both the recovery process and safeguarding the main characteristics of its historic fabric (Figure 9).

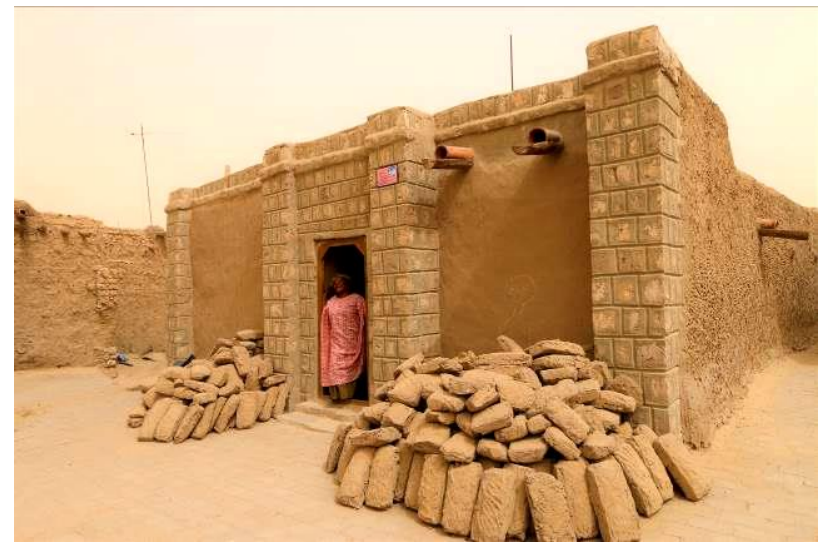

Figure 9. Restored house of widow Nana Ber, ready to carry on with additional repairs $\odot$ Joffroy T. CRAterre.

26 AIMF, association Internationale des Maires Francophones, Paris. www.aimf.asso.fr

\section{THE SITUATION IN EARLY 2020}

Five years after the completion of the mausoleum reconstruction project it is already a good time to undertake a post-project evaluation. For this, most of the mausoleums have been visited while some interviews were carried out with some of the custodian families and masons responsible for protection and maintenance. An interesting issue revealed by this inquiry (Cissé, 2020) is that all the mausoleums have recovered their importance among the local people. This is reported in a variety of degrees, illustrated by an overall evaluation of visits from worshippers and estimate to be from 50 to $100 \%$ compared to the situation before 2012. It is difficult however to take these figures for granted as some of the mausoleums are not overseen on a permanent basis while on the other hand visits could also be associated with custodians looking for revenue ${ }^{27}$.

However, when looking at the state of conservation, the situation is less positive. The inside of the mausoleums is kept clean and well maintained, but the external plastering has been washed away in most places, with a serious impact on the eastern elevation, the most exposed to the driving rain during the rainy season in Timbuktu (an average of 5 heavy rains per year). In fact, after 5 years the plastering should have been done at least once at every mausoleum, but only one of them (that of Cheikh Sidi Mahamane al Foulani al Macini, located in Kabara) benefited from this traditional maintenance practice. While the masons everywhere obviously have very good knowledge of what should be done and of the "maintenance guide" drawn up within the project, it appears that nothing has been done while the condition of some of the mausoleums should be cause for their concern (Figure 10).

The responses given by the custodians here are vague, often referring to the difficulties to get the right materials for the maintenance, or saying that today maintenance should be decided by professionals and done under their supervision. Though there is probably a financial aspect linked to this "wait and see" behaviour. Even though the custodians probably receive some tips/gifts from visitors/worshippers, they are not convinced that these should fund the works or even justify the purchase of the materials needed. For their part, the masons also probably expect to be paid for the work to be done. The overall cost would not be excessive but they seem to be acting on principle.

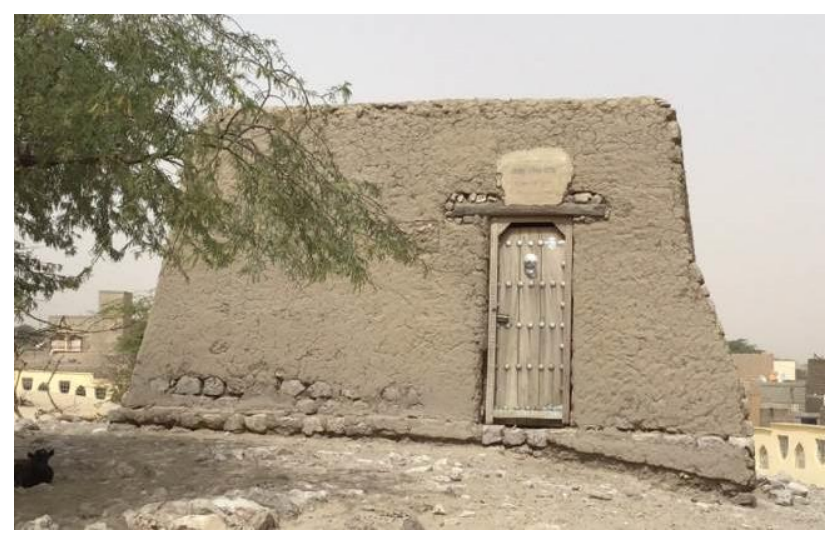

Figure 10. Mausoleum of Cheik Alpha Moya in January 2020. (c) Essayouti B. MCB.

\footnotetext{
27 The tradition involves giving a gift to the Saint, collected by the custodian family who allow believers to enter the mausoleum and so be close to the Saint to express their wishes. The medium-size mausoleums actually function like a piggy banks, opened when needed, including for the maintenance.
} 
The fact is that security in Mali has not yet improved to the point where all traditional activities have fully recovered. This has penalised the old ruling families in Timbuktu, while favouring the emergence of a new "upper social class", consisting of those who have found work at MINUSMA and other international organisations in the city. This results in tensions and an overall socio-economic environment in which individuals are more likely to seek personal gain than to display altruistic behaviour. While feeling responsible, the masons and mausoleum custodians can hardly be immune to such an ingrained logic.

\section{CONCLUSIONS}

The destruction of the mausoleums of Timbuktu has been a shock, firstly for the people of Timbuktu and their culture, and also for all Mali and the overall international community. It has revealed how strongly the Wahhabi fundamentalists are willing to destroy other Islamic cultures, especially Sufi influence, which recognises the sanctification of the holy and the wise continuing the ancient African traditions of animist belief.

Following its role as protector of cultural diversity, UNESCO has rushed to support the Malian government with the help of the international community ${ }^{28}$. By gathering together a set of national and international experts, it managed to set up a strategic plan that proved to be efficient, even if it took much longer to implement than expected due to the overall security situation.

The project efficiently adopted a holistic approach, giving equal importance to tangible and intangible facets of Timbuktu culture. This was much appreciated by the local people and had a paramount role in rebuilding their self-confidence and pride. This was reinforced by the ruling from the International Court of Justice in September 2016 and the admission of guilt by Ahmed Al-Faqi Al-Mahdi, who had played a paramount role in the destructions, including that of the Sidi Yahai sacred door. In more technical terms, the reconstruction process has been an opportunity to document and reveal this specific culture and the importance which should be assigned to such modest built heritage. It is now better-known in terms of fabric and the practices linked to this, construction, maintenance, beliefs and practice, and its values have been recovered and recognised, which is an important asset for the future. The reconstruction has also been a chance to collect oral building traditions and practices, to crosscheck a variety of sources and check some of them in situ. The result has been recorded in several documents (Koné et al., 2016) so that there are now reference documents for immediate use, with the potential to revise versions in the future based on longer-term observations, and possibly translated into the local language. In addition, about 40 younger masons were trained and can now be mobilized for construction and maintenance of the mausoleums and mosques, and also for the conservation of the old city fabric.

The traditional building techniques have been revalorised and there is revived interest within the community. However, projects funded by international organisations have led to increased costs in labour and some traditional materials (e.g. palm trunk beams), and the taste for modern construction materials and techniques is still very much alive.

\footnotetext{
28 France played a leading role in the early phases, while the European Union and Swiss cooperation took over for the reconstruction process with contributions from other countries. MINUSMA also played an important role in guaranteeing transport and safety measures for national and international experts.
}

The current socio-economic situation arising from an unresolved conflict and continuing fear for personal safety is hindering local development. A dramatic illustration of this situation is that in spite of the rather good rainy seasons of these past years people in the rural areas tend to leave their farms and gardens uncultivated. Thus, the traditional activities of the mausoleum custodians are poorly developed while somehow everyone is trying to get other sources of revenue, which depend more on the international presence.

In these conditions, the "wait and see" attitude towards the maintenance of the mausoleums can hardly be surprising. Moreover, taking stock of the history of the state of conservation of the monuments in Timbuktu (Ould Sidi, 2006), and observing some old pictures of the mosques in detail, it appears that such states of conservation, showing seriously eroded stone-earth masonry, have been repeated over time. And there are quotes from generous donors who have come to save them. At times this can be an opportunity to make some changes ${ }^{29}$, improvements, and probably for the masons to practice and improve their art of building while also reinforcing their sense of ownership and possibly their willingness to freely undertake maintenance.

At present, the monuments in Timbuktu are living heritage. They have always evolved over time both with annual cycles (that of the rain and the erosion of the plastering it entails); that of regular maintenance (every three to five years); repairs of structural pathologies, often adding buttresses ${ }^{30}$; and at times more important works, including extensions and raising of the roof structure.

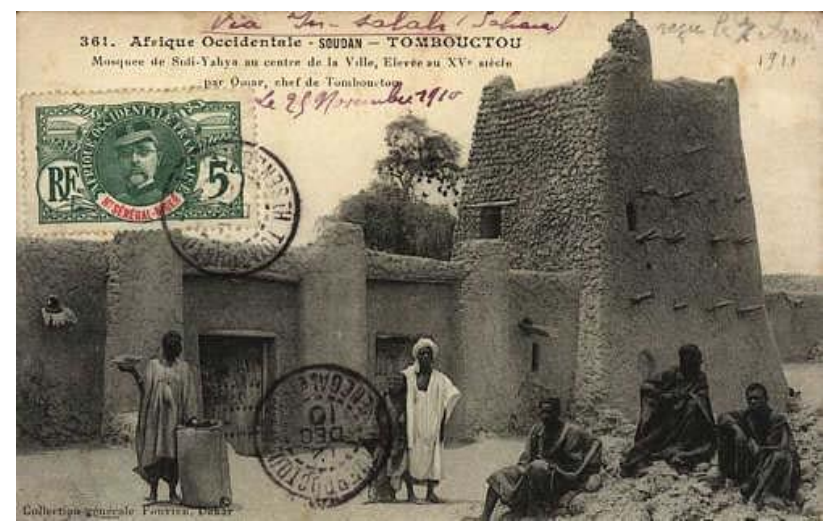

Figure 11. Postcard sent on 25 November 1910 showing Sidi Yahia Mosque with serious erosion of the eastern elevation of its minaret. (Collection Fortier - archives MCT).

How to take that into account while trying to guide and assist the local people in their self-capacity, their resilience in keeping their heritage as they have done for over 600 years? What should be done and to what extent? Who should be responsible for what? These are very difficult questions. And it is most probable that they will remain so for a long time and will entail negotiations with all the local stakeholders (masons, custodians, Imams, local authorities, government representatives) and all potential contributors present.

\footnotetext{
29 This occurred recently, in 2011, when one such generous donor provided funding for the laying of glazed tiles over the entire surface of the courtyard of Sidi Yahia mosque. After some negotiations with the Imam, these were removed in 2014 as this "improvement" had turned into a threat.

30 The use of buttresses is a common practice. They are frequently found in the mosques and are also in some of the mausoleums, in particular that of Alpha Moya, where they give it its specific shape.
} 
This is an exercise well mastered by the people of Timbuktu. One should not forget that, if Timbuktu is promoting itself as a holy place and the oldest spiritual and academic knowledge centre $^{31}$ in the area, it was founded and developed as a trading port at the edge of the Saharan desert and as such has also been renowned for its high knowledge and ability to bargain.

Still let us hope that this situation of conflict will end very soon allowing traditional activities to ensure the wealth of the city and increase the resilience of its people. Moreover, recovery of a peaceful environment would certainly allow Timbuktu to recover its holy city status. Of course, this would also revive it as a major religious and cultural tourist attraction. Once peace is restored there will be increased self-capacity and numerous opportunities to fund the maintenance of the mausoleums and mosques. This will hopefully involve the old city centre as a whole, which deserves to be included as part of this major World Heritage Site in Africa.

\section{ACKNOWLEDGEMENTS}

The authors would like to thank all those who have contributed to this reconstruction project. These acknowledgements first go to the Ministry of culture of Mali for its constant trust as well as to UNESCO, specifically its successive Resident representatives in Bamako. They also go to all the donors (including the EU and the Governments of France and Switzerland.) who have given assistance or provided the funds for undertaking the numerous missions in situ as well as to MINUSMA which ensured security conditions for undertaking our work in the field. We also wish to thank the people of Timbuktu who have participated very actively in the project. Special thanks go to the head and members of the masons' corporation of Timbuktu who had a paramount role in getting pertinent information while also implementing the reconstruction project in the field.

\section{REFERENCES}

Apollonj Ghetti, P. M., 2014. Etude sur les mausolées. Paris, UNESCO.

Atelier d'Architecture Aldi, 2013. Relevés architecturaux / Etat des lieux des mausolées détruits à Tombouctou / Réhabilitation. Bamako, MCAT.

Bertagnin, M., Ould Sidi, A., 2014. Manuel pour la conservation de Tombouctou. Paris, UNESCO.

Cissé Alpha, O., 2020. Rapport d'investigation sur les mausolées. [S.1.]. MCT.

Cissé, L., Joffroy, T., Guindo, P., 2010. Le temple d'Arou. Falaises de Bandiagara, Pays Dogon Grenoble, CRATerreENSAG. ISBN 978-2-906901-63-6.

Elondou, L., Cissé, L., 2018. Reconstruction des mausolées de Tombouctou: le rôle des communautés locales. Patrimoine mundial: reconstruction et recouvrement, 86, p. 6 .

Elondou L.A., Guesdon, M. G., Joffroy, T., Keita, B., Diallo, S., Stehl, D., Rashti, C., 2013. Mission conjointe en vue de

31 This is especially true of Sankore University which is said to have had up to 25000 students at the end of the 15 th century. l'évaluation du patrimoine culturel malien et des manuscrits anciens. Bamako et Tombouctou, 28 mai - 8 juin 2013. Paris, Bamako, UNESCO, MCAT.

Joffroy, T., et Al., 2016. Rapport // Etude de la construction à Tombouctou. Région Rhône-Alpes, Régionde Tombouctou, DNPC, CRAterre, Editions CRAterre.

Kone, M., et Al., 2016. Guide d'entretien des mausolées reconstruits et réhabilités de Tombouctou. Paris, Bamako, UNESCO, MCAT.

MCAT, 2015. Travaux de reconstruction des mausolées de Tombouctou: cahier des prescriptions techniques particulières. Paris, Bamako, UNESCO, MCAT, Minusma.

Ould Alhadje, S., 2014. Etude historique sur les 16 mausolées du patrimoine mondial de Tombouctou et sur les mausolées non classés ayant une importance majeure. Place, Editorial.

Ould Sidi, A., 1995. Les travaux saisonniers de réparations des mosquées de Tombouctou. Tombouctou, Mission Culturelle de Tombouctou.

UNESCO, 2013. International meeting of experts on the safeguarding of Mali's cultural heritage: action plan for the rehabilitation of cultural heritage and the safeguarding of ancient manuscripts in Mali. Paris, UNESCO.

UNESCO, 2013. Patrimoine endommagé des régions Nord du Mali: Document de projet, Octobre 2013. Paris, UNESCO.

UNESCO, 2014. Stratégie de reconstruction des biens du patrimoine mondial du nord du Mali: Tombouctou, Tombeau des Askia et autres biens affectés- fev. 2014. Bamako, UNESCO.

UNESCO. Tombouctou. La Liste du Patrimoine mundial. Available at: http://whc.unesco.org/fr/list/119/ 